\title{
Extracellular Thiol Isomerases and Their Role in Thrombus Formation
}

\author{
Sol Schulman, ${ }^{*}$ Pavan Bendapudi, ${ }^{*}$ Anish Sharda, Vivien Chen, Lola Bellido-Martin, \\ Reema Jasuja, Barbara C. Furie, Robert Flaumenhaft, and Bruce Furie
}

\begin{abstract}
Significance: The mammalian endoplasmic reticulum (ER) houses a large family of twenty thioredoxin-like proteins of which protein disulfide isomerase (PDI) is the archetypal member. Although the PDI family is best known for its role in oxidative protein folding of secretory proteins in the ER, these thioredoxin-like proteins fulfill ever-expanding roles, both within the secretory pathway and beyond. Recent Advances: Secreted PDI family proteins have now been shown to serve a critical role in platelet thrombus formation and fibrin generation. Utilizing intravital microscopy to visualize thrombus formation in mice, we have demonstrated the presence of extracellular PDI antigen during thrombus formation following injury of the vascular wall. Inhibition of PDI abrogates thrombus formation in vivo $(16,26,46,55)$. These observations have been extended to other PDI family members, including $\operatorname{ERp} 57(39,116,118,123)$ and ERp5 (77). The vascular thiol isomerases are those PDI family members secreted from platelets and/or endothelium (40): PDI, ERp57, ERp5, ERp72, ERp44, ERp29, and TMX3. We focus here on PDI (16, 46, 55), ERp57 (39, 116, 118, 123), and ERp5 (77), which have been implicated in thrombus formation in vivo. Critical Issues: It would appear that a system of thiol isomerase redox catalysts has been hijacked from the ER to regulate thrombus formation in the vasculature. Future Directions: How this redox system is trafficked to and regulated at the cell surface, the identity of extracellular substrates, why so many thiol isomerases are required, and which thiol isomerase functions are necessary are critical unanswered questions in understanding the role of thiol isomerases in thrombus formation. Antioxid. Redox Signal. 24, 1-15.
\end{abstract}

\section{Thrombus Formation}

$\mathbf{T}$ HROMbUS FORMATION is a host defense mechanism to minimize the loss of blood following a breach in the high-pressure circulatory system (30). Under normal physiologic conditions, thrombus formation preserves the normal blood pressure. Under pathologic conditions, thrombi fail to form, leading to bleeding, or are formed inappropriately, leading to blockage of arteries and veins and ischemia of distal tissue. We and others have demonstrated the importance of vascular thiol isomerases during thrombus formation following injury of the vascular wall, including protein disulfide isomerase (PDI) (16, 26, 46, 55), ERp57 (39, 116, 118, 123), and ERp5 (77). These enzymes are required for platelet thrombus formation and fibrin generation.

\section{Overview of Thiol Isomerases}

There are 20 known members of the thiol isomerase family (Fig. 1), PDI being the best known since the pioneering work of Anfinsen and colleagues $(19,34)$. PDI family proteins share at least one thioredoxin-like fold, a molecular scaffold consisting of a four-stranded antiparallel $\beta$ sheet surrounded by three $\alpha$ helices (82). Eleven of these proteins contain at least one and as many as four active site Cysteine-X-XCysteine (CXXC) motifs that can alternate between the disulfide and dithiol states to transfer electrons in redox processes. Eight of these thioredoxin domain-containing proteins are redox inactive, either lacking any functional CXXC motif (ERp27, ERp29, etc.) or possessing a substitution of a single CXXC motif cysteine coupled with serine 


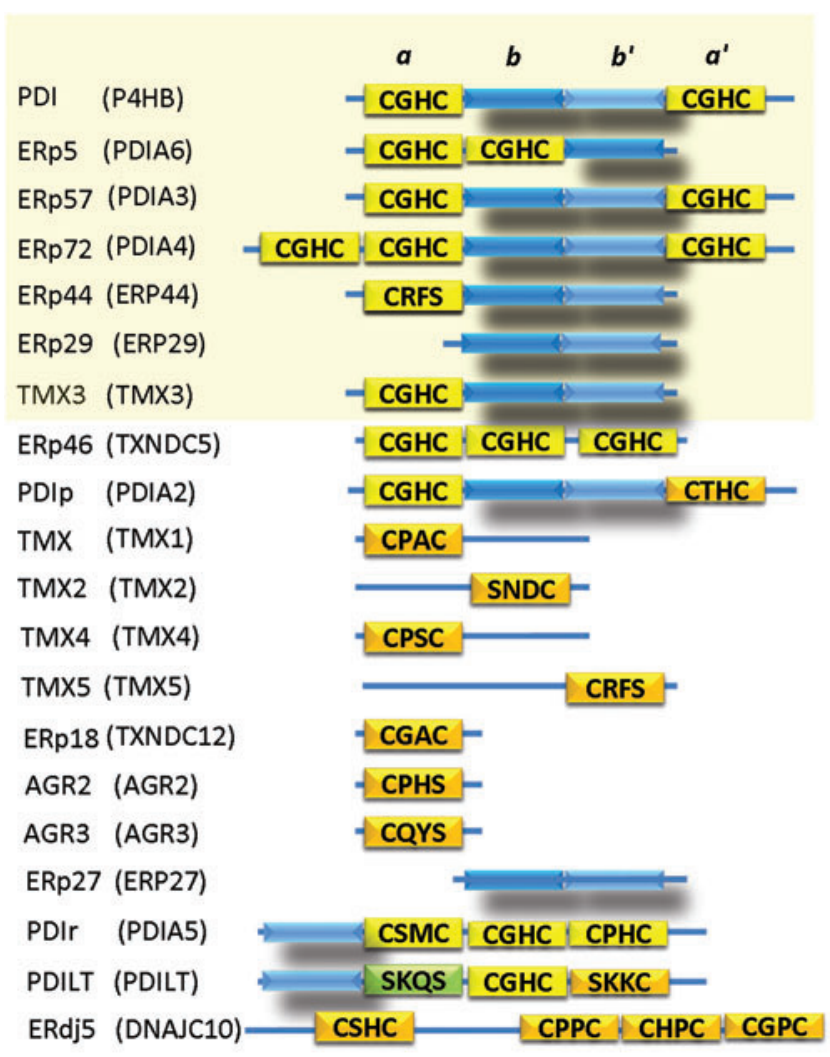

FIG. 1. PDI family of thiol isomerases. PDI is the archetypal member of the thiol isomerase family. It contains four domains $\left(a, b, b^{\prime}, a^{\prime}\right)$, including catalytically active thioredoxin-like domains containing the CGHC motif (yellow). Catalytically inactive thioredoxin-like domains are shown in blue and light blue. The vascular thiol isomerases are displayed with a pale yellow background. Family members known to be involved with thrombus formation include PDI, ERp57, and ERp5. Adapted from (26). To see this illustration in color, the reader is referred to the web version of this article at www.liebertpub.com/ars

(ERp44, TMX2, etc.). Others contain additional domains such as the $\mathrm{J}$ domain (ERdj5) or a single transmembrane segment (TMX, TMX4, etc.). While many of these proteins have been purified and studied in vitro, the unique function and endogenous substrates of most PDI family proteins remain uncertain $(4,37)$.

\section{Protein Disulfide Isomerase}

PDI is the best characterized and most abundant thioredoxin-like protein in the ER. A polypeptide with a molecular weight of 57,000 encoded by the $P 4 H B$ gene consists of four thioredoxin domains designated a-b- $b^{\prime}-a^{\prime}$, with the a and $\mathrm{a}^{\prime}$ domains, including catalytic active sites containing a Cysteine-Glycine-Histidine-Cysteine (CGHC) motif $(34,58)$. An intervening " $\mathrm{x}$ " segment is C-terminal to the $b^{\prime}$ domain and a short " $c$ " segment is C-terminal to the $a^{\prime}$ domain. These four independent domains are folded into a twisted U-shaped conformation to create the putative substrate binding groove within its cleft (113) (Fig. 2).

PDI was originally identified as the microsomal disulfide interchange activity capable of accelerating the oxidative folding of ribonuclease $\mathrm{A}$, a protein that contains four

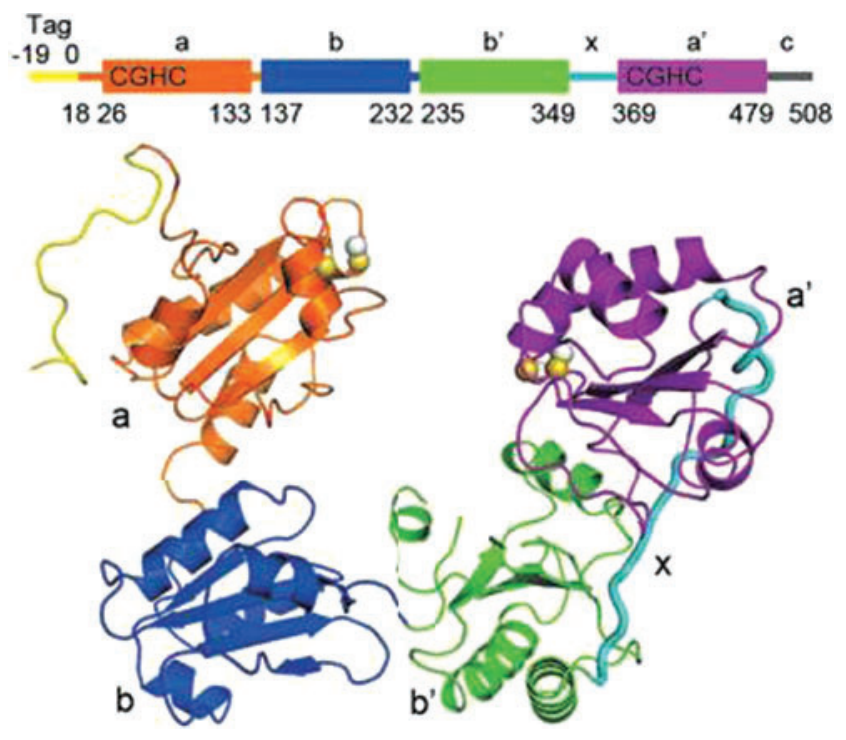

FIG. 2. X-ray crystal structure of reduced human PDI. PDI is composed of four thioredoxin-like domains: $a, b, b^{\prime}$, and $\mathrm{a}^{\prime}$. The CXXC active site motifs are found in a and $\mathrm{a}^{\prime}$. The $b^{\prime}$ domain is thought to be important for substrate specificity. This U-shaped protein appears flexible, and the a and $\mathrm{a}^{\prime}$ domains can interact simultaneously with the substrate protein. The four domains have the characteristic thioredoxin-like fold, homologous to thioredoxin. From (113). To see this illustration in color, the reader is referred to the web version of this article at www.liebertpub.com/ars

disulfide bonds $(34,108)$. A number of specific oxidative folding substrates have been described for PDI in the ER, including procollagen (27), thyroglobulin (20), and $\gamma$-gliadin (9). Beyond its role in disulfide oxidation, reduction, and isomerization reactions, PDI also acts as a noncatalytic chaperone in complex with a variety of enzymes to facilitate, for example, the hydroxylation of proline (78) and membrane transport of triglycerides (117). The entrance of PDI into the ER is specified by a cleavable N-terminal signal sequence containing the $\mathrm{C}$-terminal KDEL ER retrieval motif (107). The a and $\mathrm{a}^{\prime}$ domain CXXC motifs of PDI appear to be predominantly reduced in vivo (4), although the redox state of these dithiols is dynamically regulated by sulfhydryl oxidases such as Ero1 $(28,106)$ to drive oxidative protein folding.

PDI is abundant in the ER. However, it is also located in small secretory granules, including the GRO- $\alpha$ granule of the endothelial cell and the T-granule of the platelet (45, 105). Following laser injury in a live mouse, PDI appears rapidly first on the surface of the endothelium and subsequently on the surface of bound platelets $(16,45)$. The binding of secreted PDI to the developing thrombus involves the interaction of PDI with the $\beta 3$ integrins, $\alpha v \beta 3$ on the endothelium, and $\alpha \operatorname{IIb} \beta 3$ on bound platelets (17). Tissue factor and PDI are colocalized on the endothelium surface following cell activation by the laser injury (Fig. 3A). The expression of PDI on the lumenal wall of an arteriole immediately follows laser injury and is rapidly followed by the expression of tissue factor (Fig. 3B). The endothelial surface is also shown. These events occur following calcium mobilization (45). Similarly, PDI has been known for some 


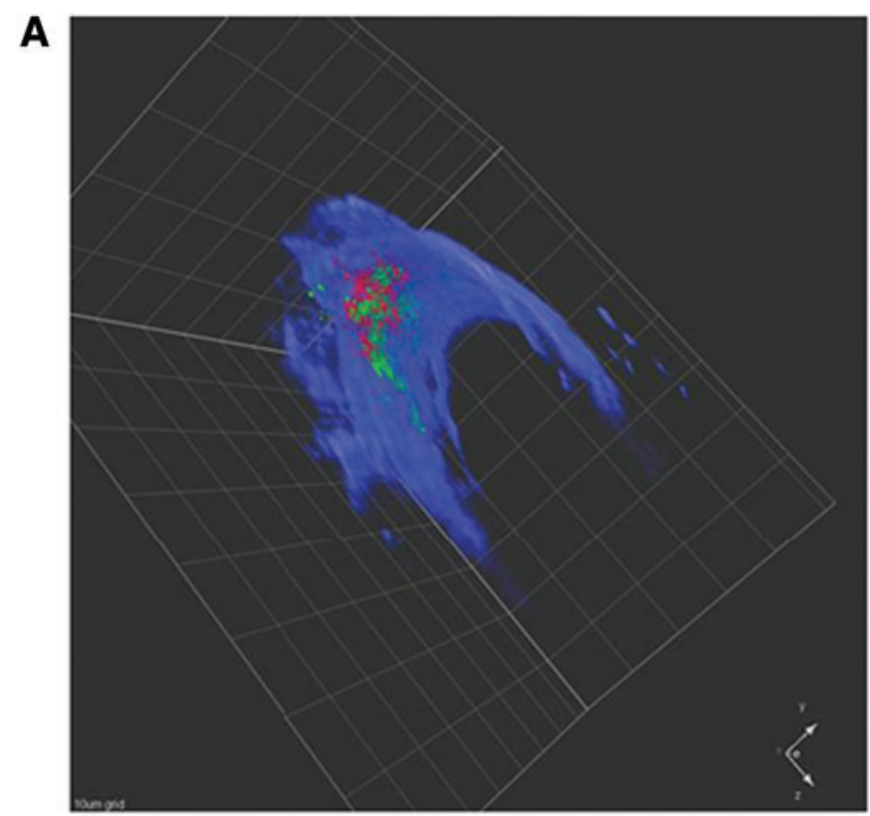

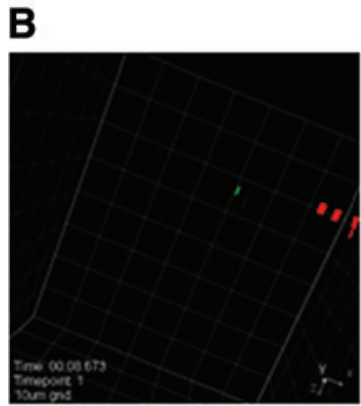

preinjury

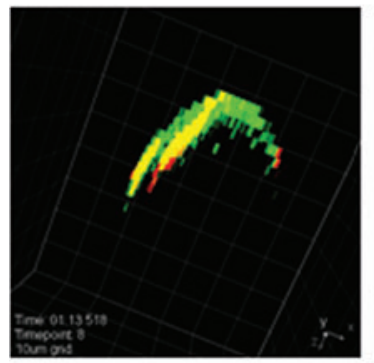

$\mathrm{T}=45 \mathrm{~s}$

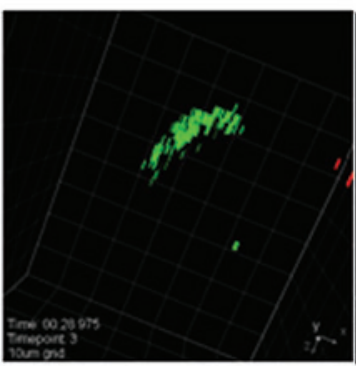

injury

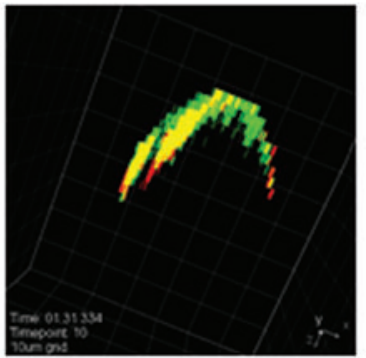

$T=65 \mathrm{~s}$

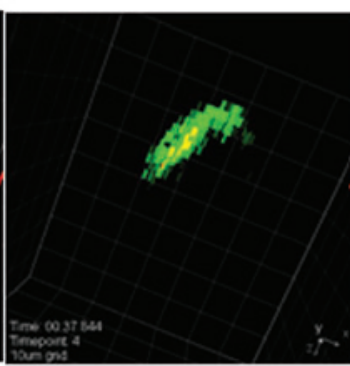

$\mathrm{t}=12 \mathrm{~s}$

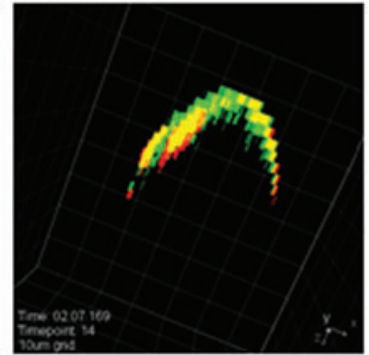

$\mathrm{T}=92 \mathrm{~s}$

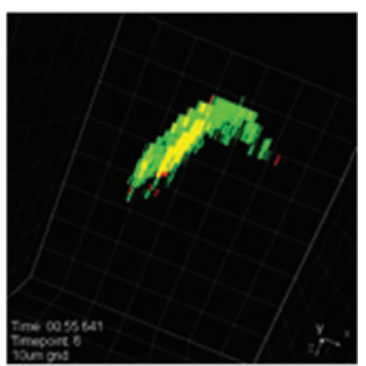

$\mathrm{t}=27 \mathrm{~s}$

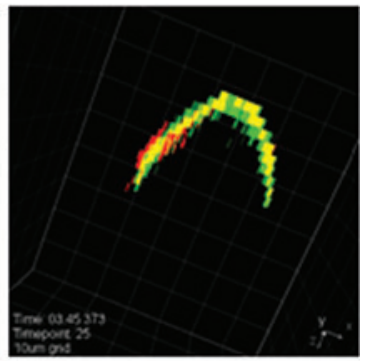

$\mathrm{T}=181 \mathrm{~s}$

FIG. 3. Three-dimensional image reconstruction from confocal stacks taken during in vivo laser injury-induced thrombus formation in the mouse. (A) This arteriole demonstrates localization of PDI (green) and tissue factor (red) with endothelium (blue). Endothelium is marked with fluorescently tagged anti-CD146 antibody, while PDI and tissue factor are designated with corresponding fluorescently tagged antibodies. (B) Sequence of confocal images of tissue factor antigen (red) and PDI antigen (green) following laser-induced injury of the vessel wall of a mouse cremaster arteriole. Merge between tissue factor and PDI is visualized as yellow. Initial injury monitored for $120 \mathrm{~s}$. Images are 3D reconstructions from confocal stacks using maximum intensity projection mode. The image coordinate arrows for x, y, z planes are provided for orientation. To see this illustration in color, the reader is referred to the web version of this article at www.liebertpub.com/ars

time to be secreted rapidly from platelets in vitro upon stimulation by platelet agonists (14).

\section{Oxidoreductase activity of PDI}

The CGHC motif active sites of PDI enable it to alternate between the reduced dithiol and disulfide-bonded states and, thus, participate in biochemical oxidation and reduction reactions. While PDI does directly oxidize disulfide bridge formation in a number of proteins, it is itself unable to generate a disulfide de novo. The oxidized form of glutathione (GSSG) is able to oxidize the PDI active site $(43,53)$, but the reaction is stoichiometric and GSSG would also need to be recycled. As such, PDI is dependent upon a true sulfhydryl 
oxidase and must itself be oxidized before it can catalyze oxidative protein folding. This is accomplished by cooperating with a sulfhydryl oxidase or a small molecule oxidant such as glutathione or molecular oxygen. At least four families of sulfhydryl oxidases reside within the eukaryotic secretory pathway. These include the ER oxidase 1 proteins (Ero1- $\alpha$ and $-\beta$ ), the quiescin-sulfhydryl oxidases (QSOX1 and 2), the vitamin K epoxide reductase paralogs (VKOR and the VKOR-like protein), and peroxiredoxin-4.

A general molecular logic unites these pathways (Fig. 4). A sulfhydryl oxidase couples the oxidation of a CXXC motif in PDI to the reduction of a small molecule cofactor; this cofactor may be a flavin adenine dinucleotide (FAD) molecule for the Ero1 and QSOX proteins or a quinone such as vitamin $\mathrm{K}$ in the case of the VKORs. The reaction proceeds through a mixed disulfide intermediate between the sulfhydryl oxidase and a catalytic thioredoxin domain of the PDI family protein that can be trapped in vivo $(3,72,93,104)$. This describes a linear electron transfer pathway supporting disulfide formation, with the enzyme first oxidizing an active site CXXC motif in PDI, which subsequently donates its disulfide to a nascent secretory protein. Some thiol isomerases preferentially pair with specific sulfhydryl oxidases, such as peroxiredoxin IV with ERp5 (92) and VKOR with TMX (94). In an additional layer of complexity, some PDI family thiol isomerases may also participate in redox cascades with one another as a bridge between sulfhydryl oxidase and the ultimately oxidized thioredoxin-like protein (74).

\section{Chaperone activity of PDI}

Chaperones share the ability to recognize and bind nonnative proteins under biophysical conditions that can promote proper folding, as occurs in the ER (8). PDI has molecular chaperone activity (115). The complete deletion of PDI in yeast is lethal, yet cells with mutant PDI that possess only inactivated catalytic sites (AXXA) are viable (62). Consistent with these observations, no viable strains of PDI knockout mice have been described (37). These findings suggest that the essential function of PDI in cell growth and survival may lie not in its catalytic activity but rather in its role as a chaperone protein. The structural determinants of PDI chaperone activity remain unclear. A mutant PDI with the 51 C-terminal amino acid residues deleted ( $\left.a b b^{\prime} \mathrm{xa}^{\prime}\right)$ lost its chaperone activity but retained its isomerase and oxidoreductase activities (18). While this result seems to indicate that the C-terminus of PDI may be necessary for its chaperone activity, the abb' $\mathrm{xa}^{\prime}$ mutant may also result in a loss of substrate binding by the $\mathrm{b}^{\prime}$ domain due to destabilization of the $\mathrm{a}^{\prime}$ domain (37). If true, this would, in turn, suggest that the main effect being observed is not the importance for chaperone activity of the c-extension but rather the critical substrate binding via the $\mathrm{b}^{\prime}$ domain. Hybrid PDI mutants that contained various combinations of PDI domains with or without thioredoxin (101) indicated that full-length PDI is required for chaperone activity but not catalytic function. The role of the $b^{\prime}$ domain in PDI's chaperone activity appears critical.

We have recently demonstrated that a specific inhibitor of PDI reductase activity identified from a high-throughput screen, quercetin-3-rutinoside, binds directly to the PDI $b^{\prime}$ domain (65). Quercetin-3-rutinoside binds to the $\mathrm{b}^{\prime} \mathrm{x}$ domain

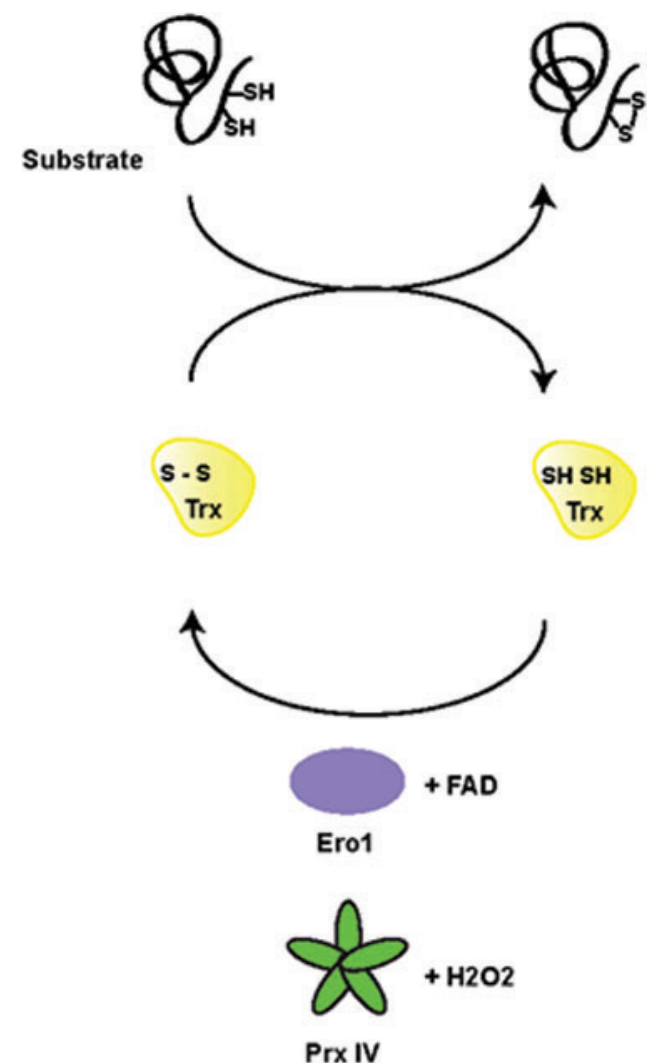

$+\mathrm{KO}$ or $\mathrm{K}$

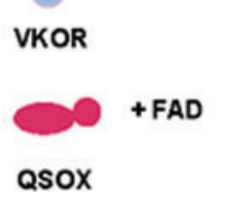

FIG. 4. Catalytic disulfide bond formation requires enzymatic reoxidation of thiol isomerases. A thioredoxinlike thiol isomerase (Trx, yellow) donates its disulfide to a reduced protein substrate with concomitant reduction of the CXXC motif cysteine residues in Trx. In order for a thiol isomerase to assist oxidation of another folding protein, the active site CXXC motif must first be reoxidized. A family of sulfhydryl oxidases exists within the mammalian secretory pathway that couple oxidation of Trx-like thiol isomerases to the reduction of small molecule cofactors (FAD, vitamin $\mathrm{K})$ or chemical oxidants $\left(\mathrm{H}_{2} \mathrm{O}_{2}\right)$. These include the endoplasmic reticulum oxidase 1 (Ero1-a and Ero1-b), quiescinsulfhydryl oxidases (QSOX1 and 2), the vitamin K epoxide reductase paralogs (VKOR and VKOR-like protein), and peroxiredoxin 4 (Prx4). To see this illustration in color, the reader is referred to the web version of this article at www.liebertpub.com/ars

and to the $\mathrm{bb}^{\prime}$ domains and inhibits PDI reductase activity. Reversal of quercetin-3-rutinoside inhibition of thrombus formation in a mouse model is observed with infusion of the PDI b'x domain (65).

A role for the chaperone function of PDI in thrombosis has been suggested. Versteeg used S-methyl methanethiosulfonate (MMTS) to inactivate the catalytic sites of PDI (109). 
PDI modified covalently with MMTS showed a significant reduction in oxidoreductase activity, but its chaperone activity was unaffected. However, both unmodified and MMTS-treated PDI significantly increased the rate of tissue factor-dependent factor Xa generation in a chromogenic assay $(99,109)$. Furthermore, the wasp venom-derived peptide mastoparan, which binds in the $\mathrm{b}^{\prime}$ hydrophobic pocket of PDI necessary for chaperone activity, inhibited the ability of bovine PDI to enhance factor Xa generation. PDI treated with $\mathrm{N}$-ethylmaleimide enhanced factor Xa generation in a manner similar to unmodified PDI (86).

\section{$P D I$ and thrombus formation}

Of uncertain physiologic relevance at the time, PDI was identified on the surface of resting platelets (22) and secreted from activated platelets $(13,14)$. The supernatant of activated platelets contained a bacitracin-sensitive activity capable of refolding disulfide-reduced RNAse to restore its function (14). Membrane impermeable thiol modifiers, anti-PDI Fab fragments, and the nonselective thiol isomerase inhibitor bacitracin impaired platelet aggregation in vitro and also prevented stable binding (40) of fibrinogen to its platelet surface receptor $\alpha_{\mathrm{IIb}} \beta_{3}$ (23). Disulfide exchange is important to the adhesion of platelets to fibrinogen, fibronectin, and collagen $(33,59,60)$. In the case of collagen, PDI exerts this effect by acting on integrin $\alpha_{\mathrm{b}} \beta_{1}$ rather than GPVI $(60,61)$.

Thrombospondin-1 was the first cell surface substrate of PDI to be identified (41), with the resulting disulfide arrangement of TSP-1 exposing a cryptic RGD motif to facilitate enhanced integrin receptor binding $(42,100)$. PDI was also demonstrated to catalyze the formation of thrombin-antithrombin-vitronectin and thrombin-antithrombin-thrombospondin-1 complexes in vitro $(24,73)$. These studies received little traction in the platelet biology field, given that numerous exogenous compounds are known to interfere with the function of hemostatic proteins and detailed mechanistic studies were lacking to understand the physiologic relevance of these findings.

The relevance of these observations was realized by in vivo studies demonstrating that inhibition of PDI prevents thrombus formation in mice $(16,87)$. Given that redox reactions require study in the native environment, the development of a high-speed digital intravital microscopy system for the study of thrombus formation in live mice proved essential for what was otherwise an unanticipated discovery (25); the release of PDI following vascular injury is required to support not only platelet aggregation but also fibrin generation. PDI antigen is rapidly detected at sites of vascular injury even before the local accumulation of platelets (16, 45). Using laser injury directed at the vessel wall, PDI antigen first appears along the vessel wall and is then followed by the accumulation of platelets. The amount of PDI generated increased with increasing platelet thrombus size. Concomitantly, fibrin appears within and around the platelet thrombus. This indicates that endothelial-derived PDI is secreted from the injured vasculature and that platelet accumulation and platelet activation lead to the release of a second wave of PDI (16). Inhibition of PDI with the blocking antibody RL90 or the small molecule, quercetin3-rutinoside, identified by high-throughput screening, inhibited both platelet thrombus formation and fibrin generation $(16,46)$.
The role of PDI in thrombus formation was also studied in a thrombosis model in which vessel injury was initiated with ferric chloride (Fig. 5). PDI antigen, not detected in the intact arteriole of the mesentery, accumulated at the site of injury. PDI antigen expression in the injured arteriole peaked at approximately $5 \mathrm{~min}$ and then slowly decreased. Thus, PDI antigen is expressed extracellularly during $\mathrm{FeCl}_{3}$-initated thrombus formation as well as following laser-induced thrombus formation.

To prove that PDI specifically plays a role in $\mathrm{FeCl}_{3}$-induced platelet thrombus formation, the effect of an inhibitory antiPDI antibody RL90 [known to cross-react with ERp57 (118)] on platelet deposition after $\mathrm{FeCl}_{3}$-induced laser injury was studied (Fig. 5). Pretreatment of mice with this antibody delayed the appearance of the initial platelet thrombus; no platelet accumulation was observed in about half of the mice treated at higher antibody doses and only about one third of injured vessels occluded within $30 \mathrm{~min}$. Markedly reduced fibrin deposition was detected following administration of this antibody. These results indicate that PDI, or possibly ERp57 as well, is important for both platelet accumulation and fibrin deposition during thrombus formation following $\mathrm{FeCl}_{3}-$ induced vessel wall injury. Quercetin-3-rutinoside, which inhibits PDI but not ERp57 activity, also blocks platelet accumulation and fibrin formation following $\mathrm{FeCl}_{3}$ exposure, confirming a role for PDI (46). This extracellular PDI release triggered by cell activation is further supported by the observations that PDI rapidly adheres to sites of tissue injury even in severely thrombocytopenic mice (87), animals treated with the $\alpha_{\mathrm{IIb}} \beta_{3}$ inhibitor eptifibatide (45), and mice genetically deficient in platelet-derived PDI (55).

PDI appears to control the initiation of thrombus formation, but the mechanism by which it does so is currently unknown. Specifically, the targets of vascular PDI enzymatic activity have not been identified although some preliminary results are available. PDI has been proposed to modulate the initiation of tissue factor activity, thus initiating the blood coagulation cascade and ultimately thrombin generation and fibrin formation (15). Tissue factor exists in an encrypted inactive form, but the molecular basis of this inactivity has been elusive. Encrypted tissue factor can be detected as a tissue factor antigen on cell surfaces that binds to factor VIIa but its procoagulant activity is diminished or absent $(6,71)$.

Competing hypotheses include the dimerization of tissue factor (7), the absence of negatively charged phospholipid or the presence of neutral or anticoagulant phospholipid (85), sequestration of tissue factor in cholesterol-rich lipid rafts $(21,97)$, and the reduction-oxidation of the Cys 186-Cys 209 allosteric disulfide bond that corresponds functionally to a molecular switch from inactive to active (15). It has been suggested that the oxidation of tissue factor to generate a disulfide bond between these two residues is the key event in converting the encrypted tissue factor into its active conformation, with PDI playing a crucial role in this process via its oxidoreductase function $(15,80)$. Cys209 in tissue factor has been reported to be constitutively S-glutathionylated (88) or S-nitrosylated (2). This modification was hypothesized to prevent formation of the proposed Cys186-Cys209 disulfide. PDI has been suggested to deencrypt tissue factor to yield active tissue factor (2), whereas the inhibition of PDI has been suggested to increase tissue factor activity via expression of phosphatidylserine (79). PDI also regulates a critical 
A

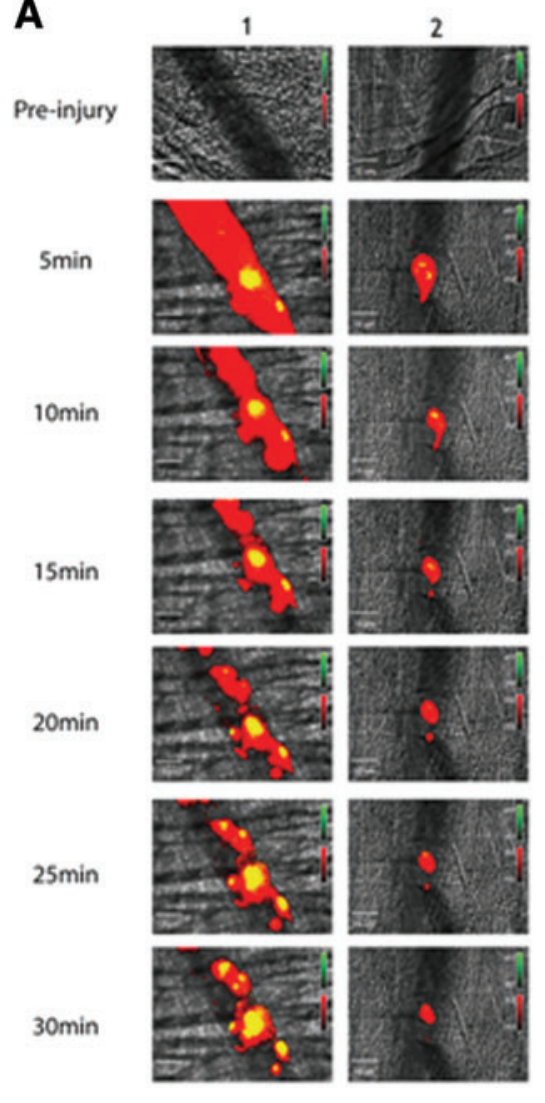

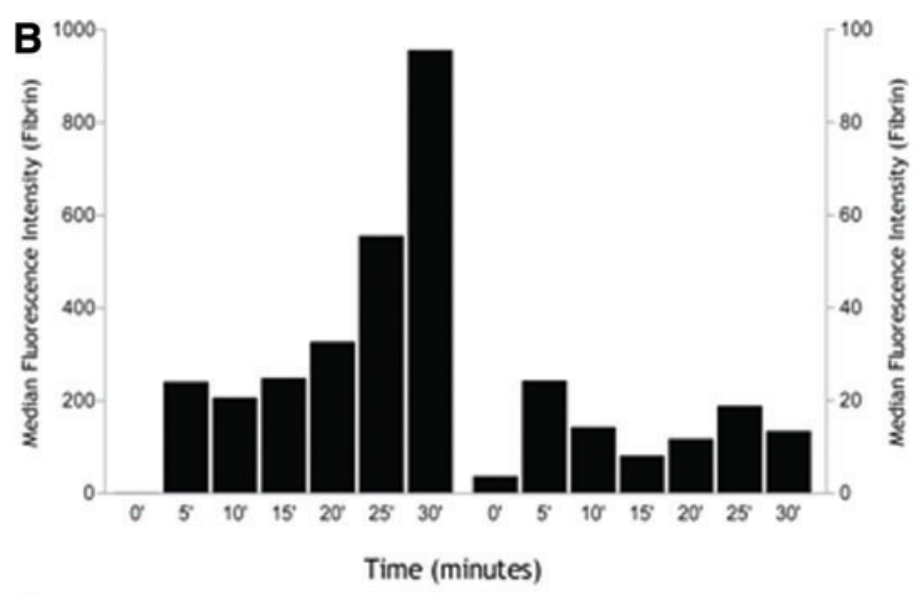

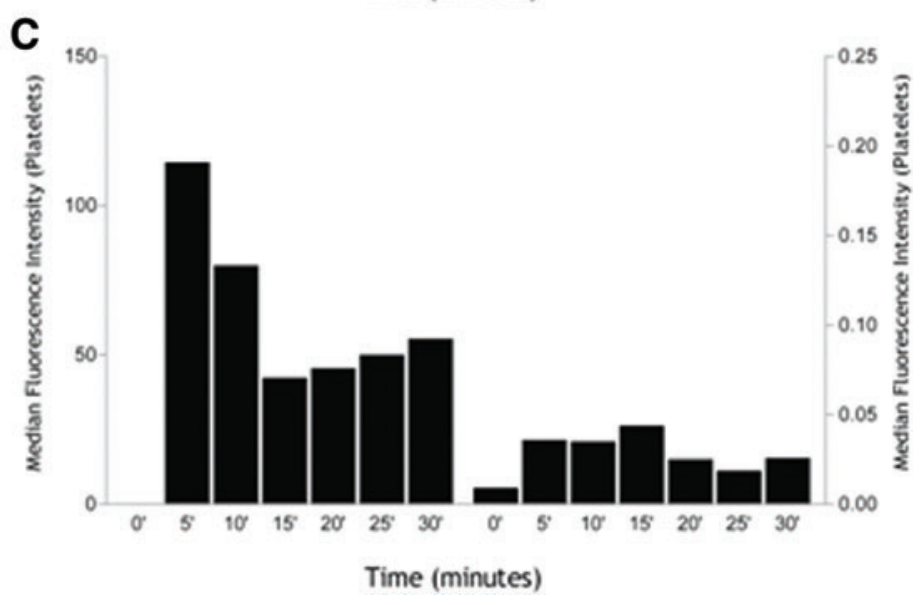

FIG. 5. Anti-PDI monoclonal antibody inhibits thrombus formation and fibrin generation after $\mathrm{FeCl}_{3}$ injury. Inhibitory anti-PDI or an isotype-matched IgG2a was infused into a wild-type mouse 10 min before $\mathrm{FeCl}_{3}$ injury. Fibrin was imaged using a fibrin-specific antibody conjugated to Alexa 488, and platelets were imaged using anti-CD42 antibodies conjugated to DyLight649. (A) The time course of appearance of fluorescence associated with fibrin and platelets as a function of time. Isotype-matched IgG2a (column 1) and inhibitory monoclonal anti-PDI antibody (column 2). (B, C) Median maximum integrated fibrin (B) and platelet (C) fluorescence infused with the IgG2a (left panels) and infused with anti-PDI antibody (right panels) versus time after arteriolar injury. This antibody has since been shown to cross react with ERp57 (118). To see this illustration in color, the reader is referred to the web version of this article at www.liebertpub.com/ars

$\mathrm{P} 2 \mathrm{X} 7$ receptor-dependent signaling pathway that is associated with the deencryption of tissue factor (31). The role of PDI in tissue factor activation remains unsettled.

Using mechanism-based kinetic trapping with active site variants of PDI, we have identified mixed disulfide intermediates between PDI and a number of novel substrates potentially critical for thrombus formation: vitronectin, complement factor 3, complement factor 5, C4b-binding protein, $\alpha 2$-macroglobulin, protein $\mathrm{S}$, histidine-rich glycoprotein, thrombospondin 1, prothrombin, and CD5 antigen-like protein (Bowley, Furie and Furie; unpublished).

\section{ERp57}

ERp57 is a single chain protein of 505 amino acids with a molecular weight of 57,000. It is expressed in eukaryotic cells from yeast to man and is widely distributed among mammalian tissues (70). Its domain structure is a-b- $b^{\prime}-a^{\prime}$, and its domains share a high degree of similarity with those of PDI. Both enzymes have four thioredoxin-like domains with the a and a' domains each characterized by a catalytic active site motif CGHC. A monoclonal antibody, RL90, that was de- veloped against PDI cross reacts with and inhibits the function of ERp57 (118), underscoring the degree of homology between the active domains of these enzymes. In contrast, the $b^{\prime}$ domain of ERp57, which is responsible for substrate binding, is distinct from that of PDI. This observation suggests that these two enzymes interact with different substrates $(38,56$, $66,90)$. That ERp57 is functionally distinct from PDI, despite their structural similarity evidenced by the fact that ERp57 cannot substitute for PDI in rescuing PDI deficiency in yeast (35). Moreover, ERp57 and PDI differ in their capacities for redox modulation by endogenous sulfhydryl oxidases such as Erol $\alpha(48,57,72)$. The gene for ERp57, PDIA3, is broadly expressed at low levels in various cell types (40), including the endothelium and megakaryocyte.

ERp57 is localized primarily to the ER of nucleated cells and contains an ER retrieval motif. A subpopulation of ERp57 escapes retention in the ER by a poorly understood mechanism and can be released into the extracellular environment, where it acts on extracellular substrates. As is the case with PDI, it is the extracellular subpopulation of ERp57 that participates in hemostasis and thrombosis. ERp57 is released from platelets upon platelet stimulation (40) and is released from the endothelium upon 
endothelial stimulation. Its location within platelets has not been determined, but it is present in the membrane fraction of endothelial cells in addition to the ER (45).

The ERp57 b' domain interacts with the ER lectin chaperones calnexin and calreticulin, while the $\mathrm{b}^{\prime}$ domain of PDI does not. Thus, intracellular substrates of ERp57 include glycoproteins that enter the calnexin cycle. Both PDI and ERp57 possess similar reduction potentials that are substantially more oxidizing than those of substrate thiols (37). Free thiol groups on the cell surface are important for normal cellular functions. Thiol isomerases on the cell membrane have multiple biological functions, including NO transport via transnitrosation $(83,122)$, redox control of exofacial protein thiols (49), and, in the case of ERp57, participation in the process of antigen presentation (67). The physiological importance of ERp57 is highlighted by the finding that the genetic knockout of ERp57 in mice leads to embryonic lethality (32).

Because ERp57 has many other well-described functions in the ER, including the processing of glycoprotein substrates of the calnexin/calreticulin cycle (76), genetic studies alone would be insufficient to distinguish between a direct extracellular role for the thiol isomerase rather than a bystander effect on another endogenous substrate of ERp57 such as various $\beta 3$ integrins. Interpreting the genetic (114) and inhibitory antibody $(39,118)$ studies together, the data favor a nonredundant extracellular role for platelet and endothelial ERp57 in thrombus formation.

\section{ERp57 in thrombus formation}

ERp57 was first detected in platelets in profiling studies designed to identity thiol isomerases in mouse and human platelets and megakaryocytes (40). These experiments showed that stimulated platelets release ERp57 and ERp57containing microparticles. A second approach used proteomics to identify proteins that are upregulated upon ligation of platelet GPVI showed that ERp57 is released from platelets upon GPVI activation (95). Polyclonal sheep anti-ERp57 antibodies inhibited platelet aggregation and adenosine triphosphate (ATP) secretion from washed platelets stimulated with CRP-XL, whereas PF4 and P-selectin expression was minimally altered (39). These results suggest the involvement of ERp57 in dense granule secretion, but not alpha granule secretion under the conditions used. Furthermore, these antibodies inhibited calcium mobilization, an early event in platelet activation, and the activation of $\alpha \operatorname{Irb} \beta 3$, as monitored by fibrinogen binding. Using an in vitro thrombus formation model utilizing collagen glass fibers, anti-ERp57 antibodies inhibited platelet accumulation. ERp57 antigen accumulated on the developing thrombus in a mouse laser injury model of thrombus formation and blocking antibodies to ERp57 inhibited platelet thrombus formation (39).

A monoclonal antibody to ERp57 inhibits platelet aggregation, whereas ERp57 enhances platelet aggregation and a mutant inactive form of ERp57 perturbs platelet aggregation (118). The activation of $\alpha \operatorname{IIb} \beta 3$ and the expression of Pselectin are inhibited by the anti-ERp57 monoclonal antibody under the conditions used. Genetically engineered mice lacking platelet-derived ERp57 have prolonged tail bleeding times and occlusion times in a mouse model of ferric chloride-induced carotid injury (116). In mesenteric arteri- oles, incorporation of ERp57-null platelets into developing thrombi induced with ferric chloride was reduced compared to wild-type platelets and platelet incorporation was dependent upon the presence of $\beta 3$ integrins. ERp57-null platelets revealed decreased platelet aggregation and decreased activation of $\alpha \operatorname{Irb} \beta 3$. ERp57 bound to $\beta 3$ in thrombin-activated platelets and not in platelets lacking $\beta 3$. These authors propose that ERp57 directly activates $\alpha \operatorname{IIb} \beta 3$ (116). These experiments were extended to the study of fibrin generation in platelets lacking ERp57 (123). Using the laser-induced thrombosis model, fibrin generation was reduced. In a mouse lacking ERp57 in the endothelium or upon addition of inhibitory antibodies to ERp57 into the mouse, fibrin generation was further reduced. These results parallel those observed for PDI $(16,45)$.

We have also evaluated the role of platelet-derived and endothelium-derived ERp57 in thrombus formation in a mouse thrombosis model using laser injury of the cremaster arteriole vessel wall. Both the stimulated endothelium and activated platelets release ERp57 at the site of thrombus formation after laser injury. The role of ERp57 in promoting platelet activation was evaluated with knocked down ERp57 in mice using a targeted antisense Vivo-morpholino that acts upstream of the translation start site of ERp57 (Vivo-ERp57). Reduction in expression of ERp57 was induced by injecting mice with $12.5 \mu \mathrm{g}$ per day per mouse of Vivo-ERp57 or control Vivomorpholino for 4 consecutive days. To determine the functional importance of ERp57 secreted from activated platelets and endothelium in vivo, we observed the kinetics of platelet and fibrin accumulation in Vivo-ERp57-treated mice. Platelet accumulation was monitored in the developing thrombus using DyLight 649-labeled anti-CD42 antibody, and fibrin deposition was monitored using an Alexa 488-labeled fibrin-specific antibody that is not reactive with fibrinogen.

Infusion of Vivo-ERp57 morpholino resulted in markedly reduced expression of ERp57 levels in platelets as well as the kidney and liver. Platelet aggregation was impaired in platelets from Vivo-ERp57-exposed mice. To determine the functional importance of ERp57 secreted from activated platelet and endothelium in vivo, the kinetics of platelet accumulation and fibrin formation was evaluated using intravital microscopy in Vivo-ERp57-treated animals. Both platelet thrombus formation and fibrin accumulation were significantly impaired in mice exposed to Vivo-ERp57 morpholino compared to control Vivo-morpholino (Fig. 6).

Our group has further explored the role of ERp57 in thrombus formation using the laser injury thrombosis model to determine how isolated deficiency of platelet ERp57 affects thrombus formation in vivo. We generated ERp57 ${ }^{\mathrm{f} / \mathrm{fl}} \mathrm{PF} 4 \mathrm{Cre}$-positive mice that did not express ERp57 in their platelets, but expression of PDI, ERp5, and ERp72 was not affected. ERp57 $7^{\mathrm{f} / \mathrm{fl}} \mathrm{PF} 4 \mathrm{Cre}-$ positive mice had a prolonged bleeding time, and ERp57 $7^{\mathrm{A} / \mathrm{f}} \mathrm{PF} 4 \mathrm{Cre}$-positive platelets failed to aggregate in response to a PAR4 agonist. In response to laser-induced vessel wall injury, platelet thrombus size in ERp57 $7^{\mathrm{f} / \mathrm{fl}} \mathrm{PF} 4 \mathrm{Cre}-$ positive mice was reduced by $85 \%$ compared to ERp5 $7^{1 / 1 / 1} \mathrm{PF} 4 \mathrm{Cre}$-negative control animals (Fig. 6). However, fibrin deposition at sites of laser injury was comparable in the two experimental and control groups (Fig. 6D). A function blocking antibody directed against ERp57 also inhibited both platelet accumulation and fibrin formation following laser-induced injury. These results indicate that under 

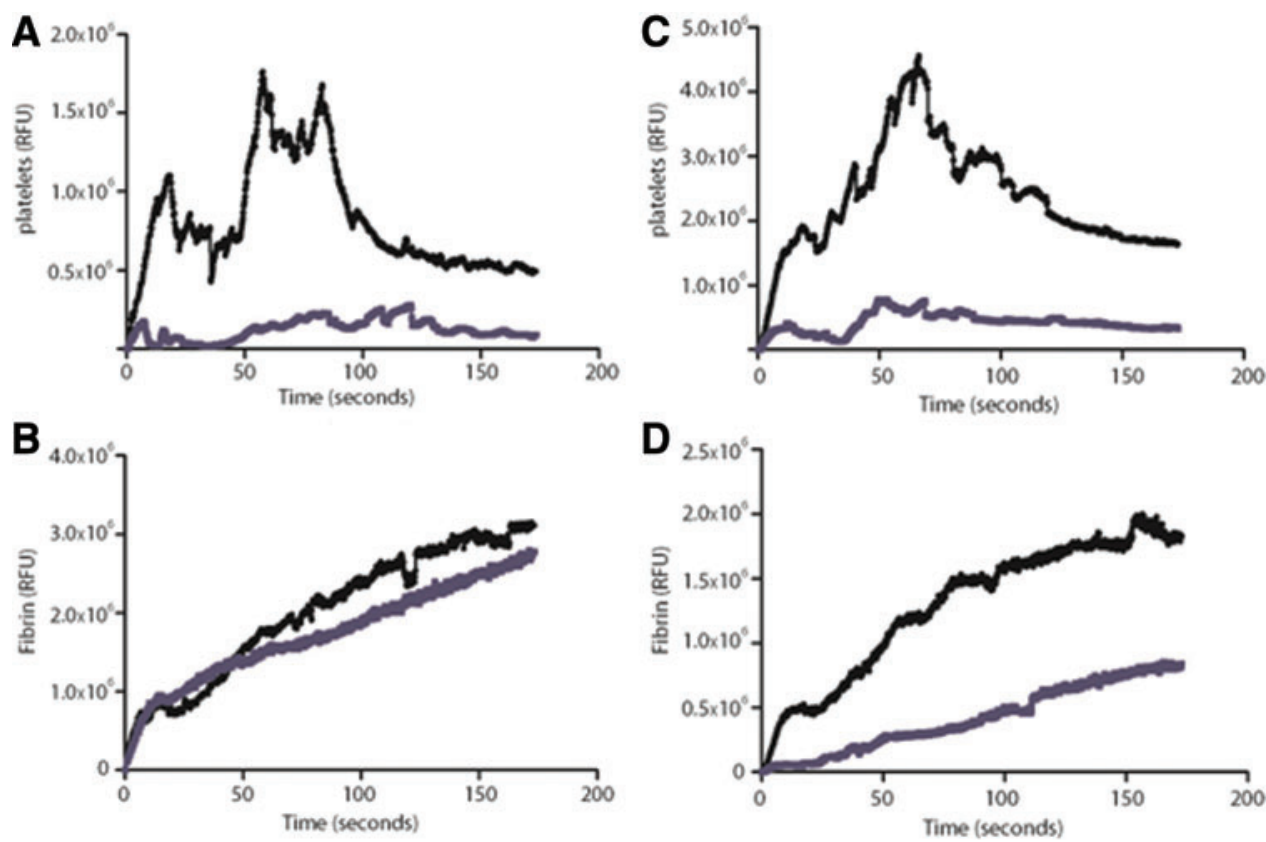

FIG. 6. ERp57 deficiency in mice studied using Vivo-morpholino anti-sense short-term elimination and animals genetically deficient in platelet ERp57. (A, B) Deficient platelet thrombus formation and normal fibrin generation in mice treated with Vivo-ERp57. Fibrin-specific mouse anti-human fibrin antibody 59D8 conjugated to Alexa 488 and anti CD-42b antibody conjugated to DyLight 649 were infused into a mouse treated with a control Vivo-morpholino or an Vivo-ERp57 $5 \mathrm{~min}$ before arteriolar injury, and thrombi were recorded. (A) Median integrated platelet fluorescent intensity or (B) median integrated fibrin fluorescent intensity presented versus time after vessel wall injury. Black, control morpholino-injected mice; gray, Vivo-ERp57-injected mice. (C, D) Platelet-independent fibrin generation in mice with ERp57 deficiency in platelets. Fibrin-specific mouse anti-human fibrin antibody 59D8 conjugated to Alexa 488 and anti-CD42b antibody conjugated to DyLight 649 were infused into ERp5 $7^{\mathrm{fl} / \mathrm{fl}} \mathrm{PF} 4$ Cre-positive or ERp $57^{\mathrm{fl} / \mathrm{fl}} \mathrm{PF} 4$ Cre-negative mice 5 min before arteriolar injury and thrombi were recorded. (C) Median integrated platelet fluorescent intensity or (D) median integrated fibrin fluorescent intensity presented versus time after vessel wall injury. Black, ERp57 ${ }^{\mathrm{f} / \mathrm{fl}} \mathrm{PF} 4 \mathrm{Cre-negative} \mathrm{mice;} \mathrm{gray,}$ ERp5 $7^{\mathrm{fl} / \mathrm{fl}} \mathrm{PF} 4$ Cre-positive mice. To see this illustration in color, the reader is referred to the web version of this article at www.liebertpub.com/ars

the conditions used, ERp57 is important for platelet thrombus generation but not fibrin generation. This contrasts with earlier results of others (123). Our experiments show that antibody-mediated inhibition of ERp57 or reduction of ERp57 expression with Vivo-ERp-57 results in reduction in fibrin deposition in wild-type mice after laser-induced injury, but mice with conditional platelet ERp57 deficiency demonstrate normal fibrin generation. This suggests that ERp57 released from endothelium is critical for fibrin generation in vivo.

Infusion of specific inhibitory antibodies to ERp57 before laser-induced injury results in diminished platelet thrombus development and fibrin generation. In contrast, plateletspecific ERp57 knockout mice show reduced platelet thrombus formation but normal fibrin accumulation. Our results demonstrate that ERp57 derived from both platelets and the endothelium following vascular injury is important to the thrombotic response. In the laser-injury model, ERp57 secreted from endothelial cells is sufficient to maintain normal fibrin accumulation but cannot restore platelet aggregation in the absence of platelet-derived ERp57.

\section{ERp5}

ERp5, encoded by the gene PDIA6, is a protein of 48,000 molecular weight containing two catalytic CGHC motifs in its a and $\mathrm{a}^{\prime}$ domains, as well as a noncatalytic thioredoxin-like fold in its b domain, which are linearly organized in a unique $a-a^{\prime}-b$ arrangement. This configuration enables catalysis of redox, isomerase, and chaperone activities, but in vitro assays of model substrates suggest ERp5 to be a less efficient thiol isomerase than PDI itself (54). Few distinct substrates of ERp5 have been identified in the ER.

Specific functions for ERp5 in the ER remain poorly characterized, although this thiol isomerase appears to undergo transcriptional upregulation by spliced XBP-1 as part of the unfolded protein response (63). Despite the presence of a classical C-terminal KDEL ER retrieval motif, many unique roles for ERp5 have been established beyond the cell surface, including thrombus formation (77) as well as in the shedding of tumor-associated ligands required for metastasis (52). For example, the extracellular catalytic activity of ERp5 acts on the tumor ligand, major histocompatibility complex class-I-related ligand MICA, and contributes to tumor immunoevasion (52).

\section{ERp5 in thrombus formation}

This enzyme expresses oxidoreductase activity, as demonstrated by the insulin reductase activity and the renaturation of ribonuclease. Like PDI and ERp57, ERp5 is secreted from platelets upon cell activation (51). Inhibition 
of ERp5 function with an anti-ERp5 antibody prevented fibrinogen binding to activated platelets and platelet aggregation in vitro (51). The fibrinogen receptor $\alpha \operatorname{IIb} \beta 3$ is a binding partner of ERp5 as the enzyme coimmunoprecipitates with the $\beta 3$ chain of the integrin (51). The involvement of ERp5 during thrombus formation was studied using the mouse laser injury model and a specific antibody raised against recombinant ERp5 (77). Anti-ERp5 antibody inhibited ERp5-dependent platelet and endothelial cell disulfide reductase activity in vitro. ERp5 antigen released at the thrombus site in a live mouse was detected after vascular injury. Anti-ERp5 at higher doses inhibited laser-induced thrombus formation in vivo by causing a major decrease in the deposition of platelets and fibrin accumulation. ERp5 binds to $\beta 3$ integrin with a $\mathrm{Kd}$ of $21 \mu M$, measured by surface plasmon resonance, and binds in the presence or absence of $\mathrm{Mn}^{++}$. The cysteine residues in the ERp5 active sites are not required for binding to $\beta 3$ integrin. These results provide evidence for a novel role of ERp5 in thrombus formation.

\section{Interaction of $\boldsymbol{\beta} 3$ Integrins and Thiol Isomerases}

The $\beta 3$ integrins of the vasculature, including $\alpha \operatorname{IIb} \beta 3$ and $\alpha \mathrm{V} \beta 3$, have been established as binding partners to extracellular PDI both in vitro and in vivo (17) (Table 1), but there is no evidence that these integrins are redox substrates of PDI. Integrins are transmembrane receptors capable of binding extracellular protein ligands that activate the integrin to induce an intracellular signaling cascade ("outside-in signaling"). $\beta 3$ integrin pairs with $\alpha \mathrm{IIb}$ on the surface of platelets and $\alpha \mathrm{v}$ on the endothelium to create the fibrinogen receptor $\alpha \operatorname{IIb} \beta 3$ and vitronectin receptor $\alpha \mathrm{V} \beta 3$, respectively. Integrin activation is accompanied by a large conformational change between the bent and elongated conformations (98) that requires a new pattern of disulfide bond formation. In the case of $\alpha \operatorname{IIb} \beta 3$, all cysteines are disulfide bonded in the closed conformation (119), but modifiable sulfhydryl groups become exposed during platelet activation $(69,120)$. PDI binds to the active form of $\beta 3$ integrin with $1-2 \mu M$ affinity (17), and small molecule or antibody inhibitors of PDI prevent activation of $\alpha \operatorname{Ilb} \beta 3$ and hence fibrinogen binding $(60,61)$.

PDI, ERp5, or ERp57 influences $\beta_{3}$ integrin function, but the mechanism is unknown. Wu reported the ability of an inhibitory antibody to ERp57 to inhibit platelet aggregation and activation of $\alpha \operatorname{IIb} \beta 3$, whereas ERp57 potentiates platelet aggregation, and the active site-mutated ERp57 inhibits platelet activation and prolongs the tail bleeding time in mice (118). Exogenous PDI binds to platelet PDI-null platelets but not to $\beta 3$-null platelets (55). Using the monoclonal antibody, PAC-1, specific for the activated conformer of $\beta 3$, we ex-

Table 1. $\beta 3$ Integrin Binding Properties of the Vascular Thiol Isomerases

\begin{tabular}{lccc}
\hline & PDI & ERp57 & ERp5 \\
\hline$\beta 3$ binding & + & + & + \\
Binding to activated $\beta 3$ & + & + & + \\
Binding to unactivated $\beta 3$ & - & - & + \\
Inactive enzyme binding to $\beta 3$ & + & $?$ & + \\
Binding constant & $1 \mu M$ & $?$ & $20 \mu M$ \\
\hline
\end{tabular}

amined the expression of this antigen in human platelets treated with PDI, ERp5, and ERp57, alone and in combination by flow cytometry. We did not observe expression of the active conformer upon incubation of PDI, ERp5, ERp57, or a mixture of PDI+ERp5+ERp57 (Fig. 7). Under the conditions studied, $\beta 3$ does not appear to be a substrate of these thiol isomerases. However, these thiol isomerases all bind to $\beta_{3}$. Therefore, it would appear that the pathway to $\beta 3$ activation involves these thiol isomerases, but they do not directly alter the $\beta 3$ conformation to express the structure associated with integrin activation.

\section{Future Directions}

Despite a firm and growing body of evidence supporting a critical role for PDI family thiol isomerases in thrombus formation and fibrin generation, a number of major questions invite future investigation.

\section{Thiol isomerase substrates involved in thrombus formation}

Although thiol isomerases are important for thrombus formation, the mechanism by which they support thrombus formation remains to be elucidated. Specifically, the identity of the substrates of each thiol isomerase needs to be defined as do the changes in structure and function that each substrate undergoes via the enzymatic action of the thiol isomerases.

\section{Redox state}

Retaining one or more CXXC motifs, the PDI family thiol isomerases are able to catalyze a variety of chemical reactions, including reduction, oxidation, isomerization, and nitrosylation/denitrosylation of substrate thiols. The reduction potential and resulting redox state of various ER-resident PDI family proteins are not identical [for review, see Hatahet and Ruddock (37)]. However, the redox state of a thioredoxinlike protein dictates the types of reactions in which it may participate. While the active site of platelet surface PDI exists in both the dithiol and disulfide states, the fraction of PDI that is reduced increased substantially upon platelet activation (10). However, it is unclear whether PDI emerged in this state or had already undergone a redox process at the time of assay. The redox state of secreted thiol isomerases remains largely unknown. Similarly, as the key substrates of secreted thiol isomerases remain to be identified, the net vector of electron flow required to support hemostasis at sites of tissue injury must also be clarified.

A limitation of much recent work on PDI family proteins in thrombus formation has been the inability to determine the redox state of the released proteins, particularly in vivo. For example, many studies demonstrate rescue or creation of a thrombosis phenotype by infusion of purified wild-type or mutant PDI or ERp57 $(46,118,123)$. Such a recombinant preparation could exist in a heterogeneous redox state, as PDI is often purified in the presence of a small molecule reducing agent that may not be completely eliminated, or alternatively, PDI may be variably oxidized by molecular oxygen during dialysis or freezer storage. Thus, unless the redox state of exogenous PDI is demonstrated before use or even at the site of action, the redox state could change following infusion. It remains unclear whether net oxidizing or reducing equivalents are introduced. 

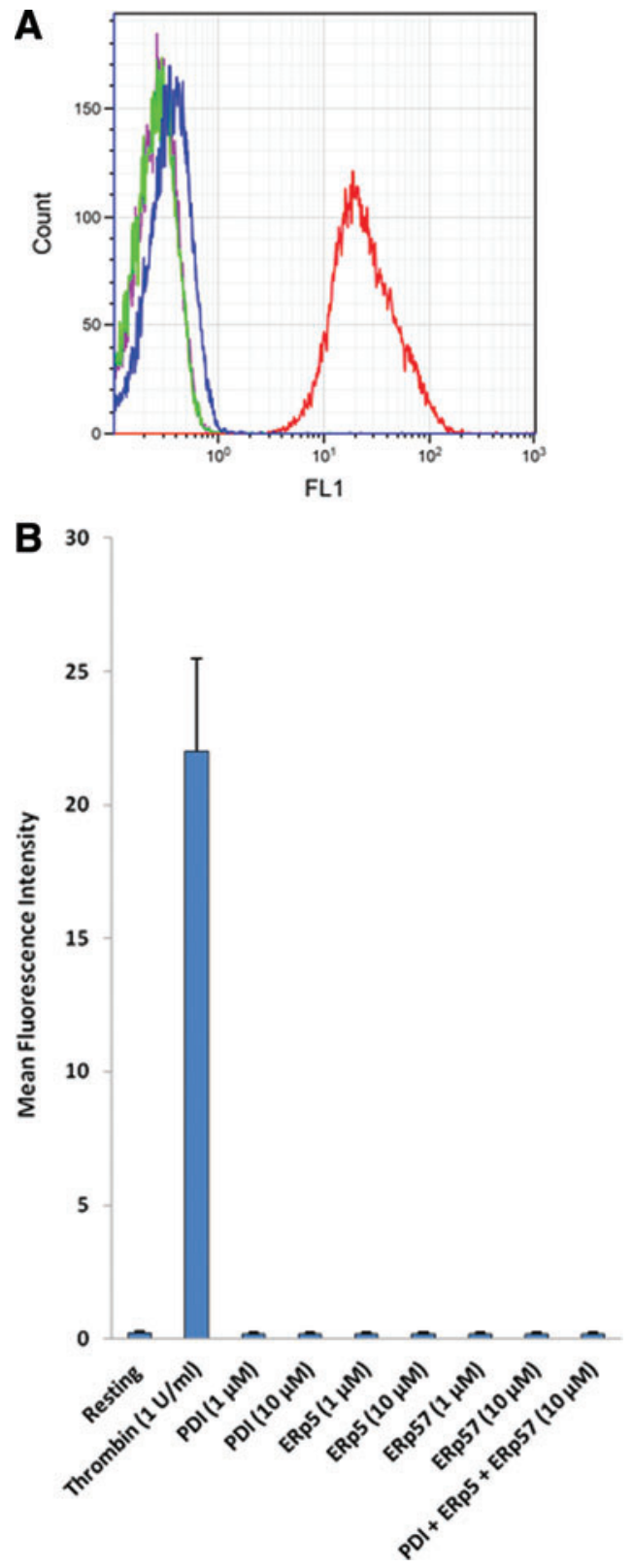

FIG. 7. Thiol isomerases do not activate $\boldsymbol{\beta 3}$. Washed human platelets were incubated with recombinant human PDI $(1$ or $10 \mu M)$, ERp5 (1 or $10 \mu M)$, and ERp57 (1 or $10 \mu M)$, either individually or in combination, in Hepes Tyrode buffer containing $5 \mu M$ reduced glutathione (GSH), $1 \mu M$ oxidized glutathione (GSSG), and $1 \mathrm{~m} M \mathrm{CaCl}_{2}$ for $10 \mathrm{~min}$ at $37^{\circ} \mathrm{C}$. Samples were then probed for activation of $\beta_{3}$ integrin using conformation-specific antibody PAC-1 (FITC-labeled) using flow cytometry. (A) Histograms showing mean fluorescence intensity for $10 \mu M$ PDI (green) and combination of PDI, ERp5, ERp57 (purple) each at $10 \mu M$ compared to resting platelets (blue) and platelets stimulated with $1 \mathrm{U} / \mathrm{ml} \alpha$-thrombin (red). (B) Mean fluorescence intensity of PAC-1 staining for various experimental conditions compared to resting platelets and platelets stimulated with $1 \mathrm{U} / \mathrm{ml} \alpha$-thrombin. Bars represent mean \pm $\mathrm{SD}$ for three separate experiments. To see this illustration in color, the reader is referred to the web version of this article at www.liebertpub.com/ars
A major question surrounds whether the redox state of these thiol isomerases is actively regulated or modified, either immediately before secretion or beyond the plasma membrane. There is clear precedent for this within the cell, where enzymes such as thioredoxin reductase help maintain a reducing cytosol via reduction of thioredoxin (5), and thiol oxidases such as Ero1 create the oxidizing environment that drives disulfide bridge formation within the $\operatorname{ER}(28,106)$. If any of the vascular thiol isomerases were to participate in a catalytic oxidative process (e.g., a single thioredoxin was to participate in multiple sequential oxidation reactions with cell surface or plasma substrates), these thioredoxin-like proteins would need to cooperate with a sulfhydryl oxidase at the cell surface. Most of the topologically extracellular thiol oxidases, including the ER oxidase 1 proteins Ero1- $\alpha$ and $-\beta$, the quiescin-sulfhydryl oxidases QSOX1 and 2, the vitamin $\mathrm{K}$ epoxide reductase paralogs VKORC1 and the VKORC1L1, and peroxiredoxin-4, are best characterized in the ER $(11,89,124)$. However, Ero1- $\alpha$ may reside on the surface of activated platelets, where its association with PDI was proposed to support activation of $\alpha \operatorname{IIb} \beta 3$ (102).

By contrast, the QSOX enzymes have an established role in the late secretory pathway (12) and are present in a variety of extracellular fluids, including plasma (44). The single transmembrane domain of QSOX1a is proteolytically processed in the Golgi to enable its cellular egress via the secretory pathway (91). Although PDI itself has limited interaction with QSOX (84), a soluble secreted form of QSOX is a cell surface sulfhydryl oxidase that could provide oxidizing equivalents to support thrombus formation. In addition, peroxiredoxin IV is secreted, binds to human umbilical vein endothelial cells, and is a serum biomarker predicting cardiovascular disease, and all cause mortality (1, 75). Another enzyme that could contribute is the extracellular gluthathione peroxidase 3 (GPx3), which metabolizes hydrogen peroxide to generate the oxidized disulfide-linked form of glutathione (GSSG) (103). Promoter mutations decreasing GPx3 expression lead to a hypercoagulable state characterized by platelet-dependent arterial thrombosis (50), and these mutations are associated with early-onset ischemic stroke (110). Generation of extracellular GSSG would indirectly bias the redox state of secreted thiol isomerases and, thus, regulate thrombosis.

\section{Redundancy or specificity}

Why are so many thioredoxin-like proteins required beyond the plasma membrane? Are there parallel and redundant pathways present to maximize redox capacity and ensure fidelity of extracellular redox reactions? Or, alternatively, are there separate and discriminatory pathways present to enable selective or regulated activation of specific substrates? As the redox potentials of the vascular thiol isomerases are not identical, one could even hypothesize that different thiol isomerases are secreted in distinct redox states, perhaps regulated by cooperation with specific thiol oxidases or reductases. ERp57 and PDI share a high degree of sequence homology, and the redox potentials for ERp57 (domain a, $-0.167 \mathrm{~V}$; domain $\left.\mathrm{a}^{\prime}-0.156 \mathrm{v}\right)$ and PDI $(-0.175 \mathrm{~V})$ are quite similar $(29,68)$. For these reasons, the question arises whether the roles of these two enzymes in thrombus formation are redundant or whether they have unique functions in this 
process. Several lines of evidence suggest the latter. Function blocking anti-ERp57 antibodies further decrease thrombininduced aggregation, ATP secretion, and $\alpha_{\mathrm{IIb}} \beta_{3}$ activation of PDI-null mouse platelets already impaired in these functions (55). A mechanism for the participation of both of these thiol isomerases in $\alpha_{\mathrm{IIb}} \beta_{3}$ activation is suggested by an elegant study of polyomavirus infection demonstrating that three thiol isomerases coordinately catalyze the unfolding of the Cterminal arm of VP1, the major coat protein of the virus, to facilitate infection (111). Alternatively or additionally, each of these thiol isomerases may interact with a unique set of substrates based on binding to their poorly conserved noncatalytic domains. The specialized role of ERp57 as a glycoprotein oxidoreductase suggests that it may be important in regulating platelet and endothelial cell surface glycoprotein function (47).

Mice specifically lacking platelet PDI suggested a defect in platelet aggregation in vitro as well as impaired platelet accumulation in vivo (55). This phenotype persisted despite upregulation of other thiol isomerases in PDI-null platelets in an apparent effort to compensate, suggesting these thioredoxin-like proteins are not redundant. One caveat is that it is difficult to distinguish impaired platelet activity due to global misfolding of platelet proteins dependent on ER PDI from a defect specific to the absence of secreted PDI. Although the defect can be rescued with exogenous PDI, it is unclear whether equimolar concentrations of other thiol isomerases would be sufficient.

\section{Beyond the ER}

Another unexplained question is how PDI and related thiol isomerases are secreted by platelets and endothelium? The vascular thiol isomerases all contain a classical C-terminal ER retrieval motif: KDEL in PDI and ERp5; QEDL in ERp57. These short peptide tags interact with a family of KDEL receptors in the early Golgi that should prevent escape to the cell surface and instead specify return of these cargos to the ER via COP-I-dependent retrograde transport (64). One could imagine a variety of mechanisms, including alternative splicing, regulated proteolysis, or posttranslational modification that would eliminate or mask the ER retrieval motif, but when examined, the KDEL sequence is preserved on the cell surface PDI (121). Other possibilities are that the retrieval motif receptors are actively downregulated or become saturated as previously described in states of ER stress (96), or that that the KDEL sequence or receptor becomes masked by interaction with chaperones or other regulatory molecules (36).

The cell biology of the endothelial cell and the platelet likely plays a critical role in PDI secretion. A KDEL receptor-dependent src kinase signaling pathway is activated by Golgi traffic (81) and has been implicated in cell surface expression of PDI in endothelial cells (112). Platelet PDI is stored in a newly described T-granule compartment that is secreted upon activation (105).

\section{Conclusion}

Thiol isomerases were originally described as intracellular actors that primarily functioned to assist in the process of protein folding. However, over the recent past, our understanding of these enzymes has expanded to include their role as extracellular regulators of thrombus formation in vivo.
While this function had not been anticipated, PDI and the other vascular thiol isomerases are now implicated at multiple steps in the thrombus formation, including their effects on platelet function and the initiation of coagulation. Although the specific mechanisms by which thiol isomerases perform this task remain to be clearly elucidated, the continued refinement of molecular probes and in vivo techniques promises to explain the role played by these regulators of thrombus formation.

\section{References}

1. Abbasi A, Corpeleijn E, Postmus D, Gansevoort RT, de Jong PE, Gans RO, Struck J, Schulte J, Hillege HL, van der Harst P, Peelen LM, Beulens JW, Stolk RP, Navis G, and Bakker SJ. Peroxiredoxin 4, a novel circulating biomarker for oxidative stress and the risk of incident cardiovascular disease and all-cause mortality. J Am Heart Assoc 1: e002956, 2012.

2. Ahamed J, Versteeg HH, Kerver M, Chen VM, Mueller $\mathrm{BM}$, Hogg PJ, and Ruf W. Disulfide isomerization switches tissue factor from coagulation to cell signaling. Proc Natl Acad Sci U S A 103: 13932-13937, 2006.

3. Alon A, Heckler EJ, Thorpe C, and Fass D. QSOX contains a pseudo-dimer of functional and degenerate sulfhydryl oxidase domains. FEBS Lett 584: 1521-1525, 2010.

4. Appenzeller-Herzog $\mathrm{C}$ and Ellgaard L. The human PDI family: versatility packed into a single fold. Biochim Biophys Acta 1783: 535-548, 2008.

5. Arnér ES and Holmgren A. Measurement of thioredoxin and thioredoxin reductase. Curr Protoc Toxicol 24: 7.4.17.4.14, 2001.

6. Bach R and Rifkin DB. Expression of tissue factor procoagulant activity: regulation by cytosolic calcium. Proc Natl Acad Sci U S A 87: 6995-6999, 1990.

7. Bach RR. Tissue factor encryption. Arterioscler Thromb Vasc Biol 26: 456-461, 2006.

8. Beissinger $\mathrm{M}$ and Buchner J. How chaperones fold proteins. Biol Chem 379: 245-259, 1998.

9. Bulleid NJ and Freedman RB. Defective co-translational formation of disulphide bonds in protein disulphideisomerase-deficient microsomes. Nature 335: 649-651, 1988.

10. Burgess JK, Hotchkiss KA, Suter C, Dudman NP, Szollosi J, Chesterman CN, Chong BH, and Hogg PJ. Physical proximity and functional association of glycoprotein 1balpha and protein-disulfide isomerase on the platelet plasma membrane. J Biol Chem 275: 9758-9766, 2000.

11. Cabibbo A, Pagani M, Fabbri M, Rocchi M, Farmery MR, Bulleid NJ, and Sitia R. ERO1-L, a human protein that favors disulfide bond formation in the endoplasmic reticulum. J Biol Chem 275: 4827-4833, 2000.

12. Chakravarthi S, Jessop CE, Willer M, Stirling CJ, and Bulleid NJ. Intracellular catalysis of disulfide bond formation by the human sulfhydryl oxidase, QSOX1. Biochem J 404: 403-411, 2007.

13. Chen K, Detwiler TC, and Essex DW. Characterization of protein disulphide isomerase released from activated platelets. Br J Haematol 90: 425-431, 1995.

14. Chen K, Lin Y, and Detwiler TC. Protein disulfide isomerase activity is released by activated platelets. Blood 79: 2226-2228, 1992.

15. Chen VM, Ahamed J, Versteeg HH, Berndt MC, Ruf W, and Hogg PJ. Evidence for Activation of Tissue Factor by an Allosteric Disulfide Bond. Biochemistry 45: 1202012028, 2006. 
16. Cho J, Furie BC, Coughlin SR, and Furie B. A critical role for extracellular protein disulfide isomerase during thrombus formation in mice. J Clin Invest 118: 11231131, 2008.

17. Cho J, Kennedy DR, Lin L, Huang M, Merrill-Skoloff G, Furie BC, and Furie B. Protein disulfide isomerase capture during thrombus formation in vivo depends on the presence of beta3 integrins. Blood 120: 9, 2012.

18. Dai Y and Wang C. A mutant truncated protein disulfide isomerase with no chaperone activity. J Biol Chem 272: 27572-27576, 1997.

19. De Lorenzo F, Goldberger RF, Steers E, Jr., Givol D, and Anfinsen B. Purification and properties of an enzyme from beef liver which catalyzes sulfhydryl-disulfide interchange in proteins. J Biol Chem 241: 1562-1567, 1966.

20. Di Jeso B, Park YN, Ulianich L, Treglia AS, Urbanas ML, High S, and Arvan P. Mixed-disulfide folding intermediates between thyroglobulin and endoplasmic reticulum resident oxidoreductases ERp57 and protein disulfide isomerase. Mol Cell Biol 25: 9793-9805, 2005.

21. Dietzen DJ, Page KL, and Tetzloff TA. Lipid rafts are necessary for tonic inhibition of cellular tissue factor procoagulant activity. Blood 103: 3038-3044, 2004.

22. Essex DW, Chen K, and Swiatkowska M. Localization of protein disulfide isomerase to the external surface of the platelet plasma membrane. Blood 86: 2168-2173, 1995.

23. Essex DW and Li M. A polyclonal antibody to protein disulfide isomerase induces platelet aggregation and secretion. Thromb Res 96: 445-450, 1999.

24. Essex DW, Miller A, Swiatkowska M, and Feinman RD. Protein disulfide isomerase catalyzes the formation of disulfide-linked complexes of vitronectin with thrombinantithrombin. Biochemistry 38: 10398-10405, 1999.

25. Falati S, Gross P, Merrill-Skoloff G, Furie BC, and Furie $\mathrm{B}$. Real-time in vivo imaging of platelets, tissue factor and fibrin during arterial thrombus formation in the mouse. Nat Med 8: 1175-1181, 2002.

26. Flaumenhaft R. Protein disulfide isomerase as an antithrombotic target. Trends Cardiovasc Med 23: 264-268, 2013.

27. Forster SJ and Freedman RB. Catalysis by protein disulphide-isomerase of the assembly of trimeric procollagen from procollagen polypeptide chains. Biosci Rep 4: 223-229, 1984.

28. Frand AR and Kaiser CA. Ero1p oxidizes protein disulfide isomerase in a pathway for disulfide bond formation in the endoplasmic reticulum. Mol Cell 4: 469-477, 1999.

29. Frickel EM, Frei P, Bouvier M, Stafford WF, Helenius A, Glockshuber R, and Ellgaard L. ERp57 is a multifunctional thiol-disulfide oxidoreductase. J Biol Chem 279: 18277-18287, 2004.

30. Furie B and Furie BC. Mechanisms of thrombus formation. N Engl J Med 359: 938-949, 2008.

31. Furlan-Freguia C, Marchese P, Gruber A, Ruggeri ZM, and Ruf W. P2X7 receptor signaling contributes to tissue factor-dependent thrombosis in mice. J Clin Invest 121: 2932-2944, 2011.

32. Garbi N, Tanaka S, Momburg F, and Hammerling GJ. Impaired assembly of the major histocompatibility complex class I peptide-loading complex in mice deficient in the oxidoreductase ERp57. Nat Immunol 7: 93-102, 2006.

33. Gofer-Dadosh N, Klepfish A, Schmilowitz H, Shaklai M, and Lahav J. Affinity modulation in platelet alpha 2 beta 1 following ligand binding. Biochem Biophys Res Commun 232: 724-727, 1997.
34. Goldberger RF, Epstein CJ, and Anfinsen CB. Acceleration of reactivation of reduced bovine pancreatic ribonuclease by a microsomal system from rat liver. $J$ Biol Chem 238: 628-635, 1963.

35. Gunther R, Srinivasan M, Haugejorden S, Green M, Ehbrecht IM, and Kuntzel H. Functional replacement of the Saccharomyces cerevisiae Trg1/Pdi1 protein by members of the mammalian protein disulfide isomerase family. $J$ Biol Chem 268: 7728-7732, 1993.

36. Hardwick KG, Boothroyd JC, Rudner AD, and Pelham HR. Genes that allow yeast cells to grow in the absence of the HDEL receptor. EMBO J 11: 4187-4195, 1992.

37. Hatahet F and Ruddock LW. Protein disulfide isomerase: a critical evaluation of its function in disulfide bond formation. Antioxid Redox Signal 11: 2807-2850, 2009.

38. High S, Lecomte FJ, Russell SJ, Abell BM, and Oliver JD. Glycoprotein folding in the endoplasmic reticulum: a tale of three chaperones? FEBS Lett 476: 38-41, 2000.

39. Holbrook LM, Sasikumar P, Stanley RG, Simmonds AD, Bicknell AB, and Gibbins JM. The platelet-surface thiol isomerase enzyme ERp57 modulates platelet function. $J$ Thromb Haemost 10: 278-288, 2012.

40. Holbrook LM, Watkins NA, Simmonds AD, Jones CI, Ouwehand WH, and Gibbins JM. Platelets release novel thiol isomerase enzymes which are recruited to the cell surface following activation. Br J Haematol 148: 627637, 2010.

41. Hotchkiss KA, Chesterman CN, and Hogg PJ. Catalysis of disulfide isomerization in thrombospondin 1 by protein disulfide isomerase. Biochemistry 35: 9761-9767, 1996.

42. Hotchkiss KA, Matthias LJ, and Hogg PJ. Exposure of the cryptic Arg-Gly-Asp sequence in thrombospondin-1 by protein disulfide isomerase. Biochim Biophys Acta 1388: 478-488, 1998.

43. Hwang C, Sinskey AJ, and Lodish HF. Oxidized redox state of glutathione in the endoplasmic reticulum. Science 257: 1496-1502, 1992.

44. Israel BA, Jiang L, Gannon SA, and Thorpe C. Disulfide bond generation in mammalian blood serum: detection and purification of quiescin-sulfhydryl oxidase. Free Radic Biol Med 69: 129-135, 2014.

45. Jasuja R, Furie B, and Furie BC. Endothelium-derived but not platelet-derived protein disulfide isomerase is required for thrombus formation in vivo. Blood 116: 4665-4674, 2010.

46. Jasuja R, Passam FH, Kennedy DR, Kim SH, van Hessem L, Lin L, Bowley SR, Joshi SS, Dilks JR, Furie B, Furie $\mathrm{BC}$, and Flaumenhaft R. Protein disulfide isomerase inhibitors constitute a new class of antithrombotic agents. $J$ Clin Invest 122: 2104-2113, 2012.

47. Jessop CE, Chakravarthi S, Garbi N, Hammerling GJ, Lovell S, and Bulleid NJ. ERp57 is essential for efficient folding of glycoproteins sharing common structural domains. EMBO J 26: 28-40, 2007.

48. Jessop CE, Watkins RH, Simmons JJ, Tasab M, and Bulleid NJ. Protein disulphide isomerase family members show distinct substrate specificity: P5 is targeted to BiP client proteins. J Cell Sci 122: 4287-4295, 2009.

49. Jiang XM, Fitzgerald M, Grant CM, and Hogg PJ. Redox control of exofacial protein thiols/disulfides by protein disulfide isomerase. J Biol Chem 274: 2416-2423, 1999.

50. Jin RC, Mahoney CE, Coleman Anderson L, Ottaviano F, Croce K, Leopold JA, Zhang YY, Tang SS, Handy DE, and Loscalzo J. Glutathione peroxidase-3 deficiency 
promotes platelet-dependent thrombosis in vivo. Circulation 123: 1963-1973, 2011.

51. Jordan PA, Stevens JM, Hubbard GP, Barrett NE, Sage T, Authi KS, and Gibbins JM. A role for the thiol isomerase protein ERP5 in platelet function. Blood 105: 1500-1507, 2005.

52. Kaiser BK, Yim D, Chow IT, Gonzalez S, Dai Z, Mann HH, Strong RK, Groh V, and Spies T. Disulphideisomerase-enabled shedding of tumour-associated NKG2D ligands. Nature 447: 482-486, 2007.

53. Karala AR, Lappi AK, Saaranen MJ, and Ruddock LW. Efficient peroxide-mediated oxidative refolding of a protein at physiological $\mathrm{pH}$ and implications for oxidative folding in the endoplasmic reticulum. Antioxid Redox Signal 11: 963-970, 2009.

54. Kikuchi M, Doi E, Tsujimoto I, Horibe T, and Tsujimoto Y. Functional analysis of human P5, a protein disulfide isomerase homologue. J Biochem 132: 451-455, 2002.

55. Kim K, Hahm E, Li J, Holbrook LM, Sasikumar P, Stanley RG, Ushio-Fukai M, Gibbins JM, and Cho J. Platelet protein disulfide isomerase is required for thrombus formation but not for hemostasis in mice. Blood 122: 1052-1061, 2013.

56. Klappa P, Stromer T, Zimmermann R, Ruddock LW, and Freedman RB. A pancreas-specific glycosylated protein disulphide-isomerase binds to misfolded proteins and peptides with an interaction inhibited by oestrogens. Eur J Biochem 254: 63-69, 1998.

57. Kulp MS, Frickel EM, Ellgaard L, and Weissman JS. Domain architecture of protein-disulfide isomerase facilitates its dual role as an oxidase and an isomerase in Erolp-mediated disulfide formation. J Biol Chem 281: 876-884, 2006.

58. Laboissiere MC, Sturley SL, and Raines RT. The essential function of protein-disulfide isomerase is to unscramble non-native disulfide bonds. J Biol Chem 270: 28006-28009, 1995.

59. Lahav J, Gofer-Dadosh N, Luboshitz J, Hess O, and Shaklai M. Protein disulfide isomerase mediates integrindependent adhesion. FEBS Lett 475: 89-92, 2000.

60. Lahav J, Jurk K, Hess O, Barnes MJ, Farndale RW, Luboshitz J, and Kehrel BE. Sustained integrin ligation involves extracellular free sulfhydryls and enzymatically catalyzed disulfide exchange. Blood 100: 2472-2478, 2002.

61. Lahav J, Wijnen EM, Hess O, Hamaia SW, Griffiths D, Makris M, Knight CG, Essex DW, and Farndale RW. Enzymatically catalyzed disulfide exchange is required for platelet adhesion to collagen via integrin alpha2beta1. Blood 102: 2085-2092, 2003.

62. LaMantia ML and Lennarz WJ. The essential function of yeast protein disulfide isomerase does not reside in its isomerase activity. Cell 74: 899-908, 1993.

63. Lee AH, Iwakoshi NN, and Glimcher LH. XBP-1 regulates a subset of endoplasmic reticulum resident chaperone genes in the unfolded protein response. Mol Cell Biol 23: 7448-7459, 2003.

64. Lewis MJ, Sweet DJ, and Pelham HR. The ERD2 gene determines the specificity of the luminal ER protein retention system. Cell 61: 1359-1363, 1990.

65. Lin L, Gopal S, Sharda A, Passam F, Bowley SR, Stopa J, Xue G, Yuan C, Furie BC, Flaumenhaft R, Huang M, and Furie B. Quercetin-3-rutinoside Inhibits Protein Disulfide Isomerase by Binding to its b'x domain. J Biol Chem 290: 23543-23552, 2015.
66. Lindquist JA, Hammerling GJ, and Trowsdale J. ER60/ ERp57 forms disulfide-bonded intermediates with MHC class I heavy chain. FASEB J 15: 1448-1450, 2001.

67. Lindquist JA, Jensen ON, Mann M, and Hammerling GJ. ER-60, a chaperone with thiol-dependent reductase activity involved in MHC class I assembly. EMBO J 17: 2186-2195, 1998.

68. Lundstrom $\mathrm{J}$ and Holmgren A. Determination of the reduction-oxidation potential of the thioredoxin-like domains of protein disulfide-isomerase from the equilibrium with glutathione and thioredoxin. Biochemistry 32: 6649$6655,1993$.

69. Manickam N, Ahmad SS, and Essex DW. Vicinal thiols are required for activation of the alphallbbeta3 platelet integrin. J Thromb Haemost 9: 1207-1215, 2011.

70. Marcus N, Shaffer D, Farrar P, and Green M. Tissue distribution of three members of the murine protein disulfide isomerase (PDI) family. Biochim Biophys Acta 1309: 253-260, 1996.

71. Maynard JR, Heckman CA, Pitlick FA, and Nemerson Y. Association of tissue factor activity with the surface of cultured cells. J Clin Invest 55: 814-824, 1975.

72. Mezghrani A, Fassio A, Benham A, Simmen T, Braakman I, and Sitia R. Manipulation of oxidative protein folding and PDI redox state in mammalian cells. EMBO $J$ 20: 6288-6296, 2001.

73. Milev Y and Essex DW. Protein disulfide isomerase catalyzes the formation of disulfide-linked complexes of thrombospondin-1 with thrombin-antithrombin III. Arch Biochem Biophys 361: 120-126, 1999.

74. Oka OB, Yeoh HY, and Bulleid NJ. Thiol-disulfide exchange between the PDI family of oxidoreductases negates the requirement for an oxidase or reductase for each enzyme. Biochem J 469: 279-288, 2015.

75. Okado-Matsumoto A, Matsumoto A, Fujii J, and Taniguchi N. Peroxiredoxin IV is a secretable protein with heparin-binding properties under reduced conditions. $J$ Biochem 127: 493-501, 2000.

76. Oliver JD, van der Wal FJ, Bulleid NJ, and High S. Interaction of the thiol-dependent reductase ERp57 with nascent glycoproteins. Science 275: 86-88, 1997.

77. Passam FH, Lin L, Gopal S, Stopa JD, Bellido-Martin L, Huang M, Furie BC, and Furie B. Both platelet- and endothelial cell-derived ERp5 support thrombus formation in a laser-induced mouse model of thrombosis. Blood 125: 2276-2285, 2015.

78. Pihlajaniemi T, Helaakoski T, Tasanen K, Myllyla R, Huhtala ML, Koivu J, and Kivirikko KI. Molecular cloning of the beta-subunit of human prolyl 4-hydroxylase. This subunit and protein disulphide isomerase are products of the same gene. EMBO J 6: 643-649, 1987.

79. Popescu NI, Lupu C, and Lupu F. Extracellular protein disulfide isomerase regulates coagulation on endothelial cells through modulation of phosphatidylserine exposure. Blood 116: 993-1001, 2010.

80. Popescu NI, Lupu C, and Lupu F. Role of PDI in regulating tissue factor: FVIIa activity. Thromb Res $125 \mathrm{Suppl}$ 1: S38-S41, 2010.

81. Pulvirenti T, Giannotta M, Capestrano M, Capitani M, Pisanu A, Polishchuk RS, San Pietro E, Beznoussenko GV, Mironov AA, Turacchio G, Hsu VW, Sallese M, and Luini A. A traffic-activated Golgi-based signalling circuit coordinates the secretory pathway. Nat Cell Biol 10: 912922, 2008. 
82. Qin J, Clore GM, and Gronenborn AM. The highresolution three-dimensional solution structures of the oxidized and reduced states of human thioredoxin. Structure 2: 503-522, 1994.

83. Ramachandran N, Root P, Jiang XM, Hogg PJ, and Mutus B. Mechanism of transfer of NO from extracellular Snitrosothiols into the cytosol by cell-surface protein disulfide isomerase. Proc Natl Acad Sci U S A 98: 9539-9544, 2001.

84. Rancy PC and Thorpe C. Oxidative protein folding in vitro: a study of the cooperation between quiescinsulfhydryl oxidase and protein disulfide isomerase. Biochemistry 47: 12047-12056, 2008.

85. Rao LV and Pendurthi UR. Regulation of tissue factor coagulant activity on cell surfaces. J Thromb Haemost 10: 2242-2253, 2012.

86. Raturi A and Ruf W. Effect of protein disulfide isomerase chaperone activity inhibition on tissue factor activity. $J$ Thromb Haemost 8: 1863-1865, 2010.

87. Reinhardt C, von Bruhl ML, Manukyan D, Grahl L, Lorenz M, Altmann B, Dlugai S, Hess S, Konrad I, Orschiedt L, Mackman N, Ruddock L, Massberg S, and Engelmann B. Protein disulfide isomerase acts as an injury response signal that enhances fibrin generation via tissue factor activation. J Clin Invest 118: 1110-1122, 2008.

88. This reference has been deleted.

89. Rost S, Fregin A, Ivaskevicius V, Conzelmann E, Hortnagel K, Pelz HJ, Lappegard K, Seifried E, Scharrer I, Tuddenham EG, Muller CR, Strom TM, and Oldenburg J. Mutations in VKORC1 cause warfarin resistance and multiple coagulation factor deficiency type 2. Nature 427: 537-541, 2004.

90. Ruddock LW, Freedman RB, and Klappa P. Specificity in substrate binding by protein folding catalysts: tyrosine and tryptophan residues are the recognition motifs for the binding of peptides to the pancreas-specific protein disulfide isomerase PDIp. Protein Sci 9: 758-764, 2000.

91. Rudolf J, Pringle MA, and Bulleid NJ. Proteolytic processing of QSOX1A ensures efficient secretion of a potent disulfide catalyst. Biochem J 454: 181-190, 2013.

92. Sato Y, Kojima R, Okumura M, Hagiwara M, Masui S, Maegawa K, Saiki M, Horibe T, Suzuki M, and Inaba K. Synergistic cooperation of PDI family members in peroxiredoxin 4-driven oxidative protein folding. Sci Rep 3: 2456, 2013.

93. Schulman S. Secretory Protein Biogenesis: from Membrane Translocation to Vitamin K-Dependent Disulfide Bridge Formation. 2010, p. xii, Harvard University, Cambridge, MA, 156 leaves.

94. Schulman S, Wang B, Li W, and Rapoport TA. Vitamin K epoxide reductase prefers ER membrane-anchored thioredoxin-like redox partners. Proc Natl Acad Sci U S A 107: 15027-15032, 2010.

95. Schulz C, Leuschen NV, Frohlich T, Lorenz M, Pfeiler S, Gleissner CA, Kremmer E, Kessler M, Khandoga AG, Engelmann B, Ley K, Massberg S, and Arnold GJ. Identification of novel downstream targets of platelet glycoprotein VI activation by differential proteome analysis: implications for thrombus formation. Blood 115: 4102-4110, 2010.

96. Semenza JC, Hardwick KG, Dean N, and Pelham HR. ERD2, a yeast gene required for the receptor-mediated retrieval of luminal ER proteins from the secretory pathway. Cell 61: 1349-1357, 1990.

97. Sevinsky JR, Rao LV, and Ruf W. Ligand-induced protease receptor translocation into caveolae: a mechanism for regulating cell surface proteolysis of the tissue factor- dependent coagulation pathway. J Cell Biol 133: 293-304, 1996.

98. Shimaoka M, Xiao T, Liu JH, Yang Y, Dong Y, Jun CD, McCormack A, Zhang R, Joachimiak A, Takagi J, Wang $\mathrm{JH}$, and Springer TA. Structures of the alpha L I domain and its complex with ICAM-1 reveal a shape-shifting pathway for integrin regulation. Cell 112: 99-111, 2003.

99. Song JL and Wang CC. Chaperone-like activity of protein disulfide-isomerase in the refolding of rhodanese. Eur $J$ Biochem 231: 312-316, 1995.

100. Sun X, Skorstengaard K, and Mosher DF. Disulfides modulate RGD-inhibitable cell adhesive activity of thrombospondin. J Cell Biol 118: 693-701, 1992.

101. Sun XX, Dai Y, Liu HP, Chen SM, and Wang CC. Contributions of protein disulfide isomerase domains to its chaperone activity. Biochim Biophys Acta 1481: 45-54, 2000.

102. Swiatkowska M, Padula G, Michalec L, Stasiak M, Skurzynski S, and Cierniewski CS. Erolalpha is expressed on blood platelets in association with protein-disulfide isomerase and contributes to redox-controlled remodeling of alphaIIbbeta3. J Biol Chem 285: 29874-29883, 2010.

103. Takahashi K, Avissar N, Whitin J, and Cohen H. Purification and characterization of human plasma glutathione peroxidase: a selenoglycoprotein distinct from the known cellular enzyme. Arch Biochem Biophys 256: 677686, 1987.

104. Tavender TJ, Springate JJ, and Bulleid NJ. Recycling of peroxiredoxin IV provides a novel pathway for disulphide formation in the endoplasmic reticulum. EMBO $J$ 29: 4185-4197, 2010.

105. Thon JN, Peters CG, Machlus KR, Aslam R, Rowley J, Macleod H, Devine MT, Fuchs TA, Weyrich AS, Semple $\mathrm{JW}$, Flaumenhaft R, and Italiano JE, Jr. T granules in human platelets function in TLR9 organization and signaling. J Cell Biol 198: 561-574, 2012.

106. Tu BP and Weissman JS. The FAD- and O(2)-dependent reaction cycle of Ero1-mediated oxidative protein folding in the endoplasmic reticulum. Mol Cell 10: 983-994, 2002.

107. Vaux D, Tooze J, and Fuller S. Identification by antiidiotype antibodies of an intracellular membrane protein that recognizes a mammalian endoplasmic reticulum retention signal. Nature 345: 495-502, 1990.

108. Venetianer P and Straub FB. Enzymic formation of the disulfide bridges of ribonuclease. Acta Physiol Acad Sci Hung 24: 41-53, 1963.

109. Versteeg HH and Ruf W. Tissue factor coagulant function is enhanced by protein-disulfide isomerase independent of oxidoreductase activity. J Biol Chem 282: 25416-25424, 2007.

110. Voetsch B, Jin RC, Bierl C, Benke KS, Kenet G, Simioni P, Ottaviano F, Damasceno BP, Annichino-Bizacchi JM, Handy DE, and Loscalzo J. Promoter polymorphisms in the plasma glutathione peroxidase (GPX-3) gene: a novel risk factor for arterial ischemic stroke among young adults and children. Stroke 38: 41-49, 2007.

111. Walczak CP and Tsai B. A PDI family network acts distinctly and coordinately with ERp29 to facilitate polyomavirus infection. J Virol 85: 2386-2396, 2011.

112. Wan SW, Lin CF, Lu YT, Lei HY, Anderson R, and Lin YS. Endothelial cell surface expression of protein disulfide isomerase activates beta 1 and beta 3 integrins and facilitates dengue virus infection. J Cell Biochem 113: 1681-1691, 2012. 
113. Wang C, Li W, Ren J, Fang J, Ke H, Gong W, Feng W, and Wang CC. Structural insights into the redox-regulated dynamic conformations of human protein disulfide isomerase. Antioxid Redox Signal 19: 36-45, 2013.

114. This reference has been deleted.

115. Wang CC and Tsou CL. Protein disulfide isomerase is both an enzyme and a chaperone. Faseb J 7: 1515-1517, 1993.

116. Wang L, Wu Y, Zhou J, Ahmad SS, Mutus B, Garbi N, Hammerling G, Liu J, and Essex DW. Platelet-derived ERp57 mediates platelet incorporation into a growing thrombus by regulation of the alphallbbeta3 integrin. Blood 122: 3642-3650, 2013.

117. Wetterau JR, Combs KA, McLean LR, Spinner SN, and Aggerbeck LP. Protein disulfide isomerase appears necessary to maintain the catalytically active structure of the microsomal triglyceride transfer protein. Biochemistry 30: 9728-9735, 1991.

118. Wu Y, Ahmad SS, Zhou J, Wang L, Cully MP, and Essex DW. The disulfide isomerase ERp57 mediates platelet aggregation, hemostasis, and thrombosis. Blood 119: 1737-1746, 2012.

119. Xiao T, Takagi J, Coller BS, Wang JH, and Springer TA. Structural basis for allostery in integrins and binding to fibrinogen-mimetic therapeutics. Nature 432: 59-67, 2004.

120. Yan B and Smith JW. A redox site involved in integrin activation. J Biol Chem 275: 39964-39972, 2000.

121. Yoshimori T, Semba T, Takemoto H, Akagi S, Yamamoto $\mathrm{A}$, and Tashiro Y. Protein disulfide-isomerase in rat exocrine pancreatic cells is exported from the endoplasmic reticulum despite possessing the retention signal. $J$ Biol Chem 265: 15984-15990, 1990.

122. Zai A, Rudd MA, Scribner AW, and Loscalzo J. Cellsurface protein disulfide isomerase catalyzes transnitrosation and regulates intracellular transfer of nitric oxide. J Clin Invest 103: 393-399, 1999.

123. Zhou J, Wu Y, Wang L, Rauova L, Hayes VM, Poncz M, and Essex DW. The disulfide isomerase ERp57 is required for fibrin deposition in vivo. J Thromb Haemost 12: 18901897, 2014.
124. Zito E, Chin KT, Blais J, Harding HP, and Ron D. ERO1beta, a pancreas-specific disulfide oxidase, promotes insulin biogenesis and glucose homeostasis. J Cell Biol 188: 821-832, 2010.

Address correspondence to: Dr. Bruce Furie Division of Hemostasis and Thrombosis Beth Israel Deaconess Medical Center and Harvard Medical School Boston, MA 02115

E-mail: bfurie@bidmc.harvard.edu

Date of first submission to ARS Central, October 11, 2015; date of acceptance, October 13, 2015.

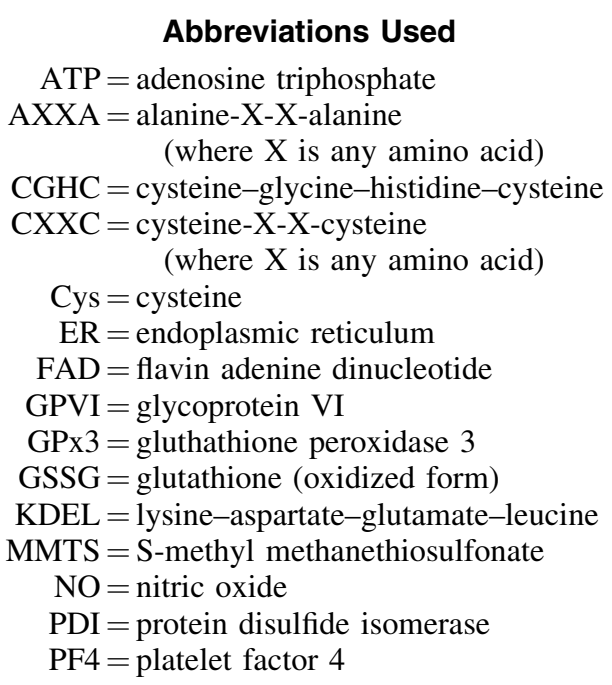

